\title{
Maternal Employment in Childhood and Adults' Retrospective Reports of Parenting Practices
}

\begin{abstract}
Do adults' perceptions of their mothers' and fathers' parenting practices in childhood vary by their mothers' employment status? Among adults in the Survey of Midlife Development in United States who lived with 2 biological parents until the age of 16 years $(N=2,246)$, those who had employed mothers during most or all of their childhood reported less support and less discipline from both parents than those who had stay-at-home mothers. Sons but not daughters who had employed mothers reported more verbal or physical assaults by both parents than their counterparts who had homemaker mothers. Despite greater social acceptance of maternal employment among younger Americans, cohort differences were not evident. These findings underscore the significance of mothers' economic roles in influencing offspring's perceptions of family dynamics.
\end{abstract}

As labor force participation among mothers increased dramatically during the latter half of the 20th century, effects of maternal employment on parental investment in childrearing have been of great interest among researchers (e.g., Hoffman \& Youngblade, 1999). Empirical stud-

\footnotetext{
*Department of Sociology, University of Maryland, 2112 Art-Sociology Building, College Park, MD 20742-1315.

Department of Sociology, Northern Illinois University, DeKalb, IL 60115 (knomaguchi@niu.edu).

Key Words: adult children, cohort, gender, life course, maternal employment, parenting.
}

ies indicate that there are no robust differences in parenting practices between employed mothers and homemaker mothers; yet, there are some differences depending on the intensity of employment. Employed mothers do not differ a great deal from nonemployed mothers in the amount of time they spend directly interacting with children (Sayer, Bianchi, \& Robinson, 2004). Employed mothers are not less strict than homemaker mothers in monitoring children's behaviors (Hoffman \& Youngblade). Some research even finds that children of employed mothers are more likely than children of homemaker mothers to report that their mothers are happier, more cheerful, and friendlier when they spend time together (Richards \& Duckett, 1994). Mothers' working longer hours, however, is associated with spending fewer hours with their children (Sayer et al., 2004) and lower levels of monitoring of their children's behaviors after school (Muller, 1995). When mothers experience greater demands and interpersonal stress at the workplace, they tend to talk less and express less affection to their children (Repetti \& Wood, 1997) and they are more likely to have arguments with their children (Crouter, Bumpus, Maguire, \& McHale, 1999).

Although many studies have been done in this area of research, relatively little is known about how children perceive their mothers' parenting practices and whether the views of children of employed mothers are different than those of children of homemaker mothers. It is important to understand children's subjective experiences with their parents because children are active 
agents who are able to understand family situations and parents' behaviors (e.g., Milkie, Simon \& Powell, 1997); hence, the effects of parents' behaviors on children's well-being often depend on how children perceive or interpret their parents' behaviors (Amato, 1987; Rohner, Bourque, \& Elordi, 1996). Limited research has found contrasting results with regard to the relationship between maternal employment and children's perceptions of their mothers' parenting practices. Using a small sample of fifth- to seventh-grade children with employed mothers in a Canadian city, Trimberger and MacLean (1982) found that although almost half of the children felt that their mothers' employment gave them special privileges or freedom, the majority reported that their mothers would have been more interested in them if they did not work. In contrast, Galinsky (1999), using a nationally representative sample of U.S. children in the 3rd to 12 th grades, reported that employment is not related to children's rating of their mothers' parenting practices such as making them feel loved, making them feel appreciated for who they are, controlling their temper when children do something that makes them angry, and so forth.

Two qualitative studies indicate that adult children have strong views of how they were raised by their parents, and the perceptions of those who had employed mothers seem to differ from those who had homemaker mothers. Sugar (1994), using a convenience sample of women in the Midwest who grew up in the 1950s through the early 1980s, found that daughters who had employed mothers during their childhood reported that they felt as if their mothers devoted too much time and energy to paid work, and that made them feel lonely and isolated. They also reported that they felt remote from their fathers and that there was more anger and frustration in their home compared with the homes of their friends whose mothers stayed at home. In contrast, interviewing adults who grew up in the 1970s and 1980 s and currently living in the New York metropolitan area, Gerson (2002) found that they generally regarded their mothers' employment as beneficial in their lives. The majority of both daughters and sons emphasized that, because of their mothers' income, their family enjoyed greater economic security and their parents provided them with greater opportunities. Their mothers became good role models of dedicated workers for them. They also said that they had a close relationship with their fathers, who were more involved in their daily lives than their friends' sole bread-winner fathers. The question of whether parents are viewed differently on the basis of maternal employment has not been tested using large nationally represented data of U.S. adults.

In this study, using data from the Survey of Midlife Development in the United States (MIDUS), we build on Sugar's (1994) and Gerson's (2002) qualitative work on the relationship between maternal employment in childhood and adults' retrospective reports of their mothers' and fathers' parenting practices while they were growing up. According to the life course perspective, experiences in childhood have long-term consequences in later stages of the life course (Elder \& Johnson, 2002). Children observe and interpret their parents' behaviors while they are young, and they bring the perceptions of how they were raised by their parents into adulthood. Although the extent to which perceptions of experiences in childhood may persist or change as children obtain adult roles is debatable (Aquilino, 1997), there is evidence that children's views of their mothers' and fathers' parenting behaviors and parent-child relationships remain relatively consistent from adolescence to adulthood (Rossi $\&$ Rossi, 1990). Adults use their retrospective perceptions of their mothers' and fathers' behaviors as parents to interpret their own current life situations such as how to interact with their own children (Townsend, 2002), how to balance work and family responsibilities (Blair-Loy, 2003), and how to evaluate the current relationship with their parents (Bedford, 1992). Perceptions of mothers' and fathers' parenting behaviors in childhood also have implications for adult's psychological well-being (Khaleque \& Rohner, 2002; Turner \& Muller, 2004).

We focus on three aspects of parenting practices that, according to previous studies, affect well-being in childhood and potentially in adulthood as well. First, children tend to thrive when they feel loved, emotionally supported, and close to their parents (Amato, 1994; Amato \& Fowler, 2002; Wenk, Hardesty, Morgan, \& Blair, 1994). Perceived lack of parental emotional support in childhood has long-term effects on children's psychological well-being in adulthood such as higher levels of depression (e.g., Khaleque \& Rohner, 2002) and hostility and drug use (Knight, Broome, Cross, \& Simpson, 1998). Second, children need consistent, moderate discipline to learn that there are limits on their behaviors, and 
parental monitoring is related to a lower risk of dropping out of high school (Astone \& McLanahan, 1991) or getting involved in delinquent behaviors (Patterson \& Stouthamer-Loeber, 1984). Third, children are affected negatively when exposed to harsh parenting, such as being slapped, spanked, or yelled at. Such children are more likely to bully others, have behavioral problems, and get poor grades (Amato \& Fowler; Straus, 1991). Perceived childhood corporal punishment also is related to adults' depressive symptoms (e.g., Turner \& Muller, 2004).

One of the major theoretical frameworks used in research on the effects of parental employment on parenting practices is role theory. Role theories provide contrasting predictions as to how employment may influence mothers' parenting practices. Role strain perspectives suggest that working mothers may experience role overload (Goode, 1960) because they tend to be responsible for the "second shift" (Hochschild, 1989) after coming home from work or because workrelated stress, such as work pressure or interpersonal stress at the workplace, "spills over" into their interactions with family members (MacEwen \& Barling, 1991). Feeling rushed, overwhelmed, or frustrated, employed mothers may not always be able to fully attend to their children in a warm, affectionate manner; they may not always be able to stick with the rules that they set for their children, such as the amount of TV watching, bedtime, or curfews; and they may be irritable and may sometimes take their frustration out on their children. In contrast, role enhancement perspectives contend that having multiple roles is better for women's well-being and that employed women are able to maintain equilibrium and perform well in many roles simultaneously (Barnett \& Rivers, 1996; Marks \& MacDermid, 1996). Employment may enhance women's sense of autonomy, self-esteem, and mental health that may lead mothers to be more responsive and less harsh toward their children (McLoyd, Jayaratne, Ceballo, \& Borqnez, 1994).

Whether employment causes strain or enhancement in mothers' parenting may depend on the intensity of employment. As we mentioned earlier, studies indicate that full-time employment might curtail mothers' time to engage with their children (Muller, 1995; Sayer et al., 2004). On the contrary, part-time employment may expand mothers' involvement in children's lives by increasing mothers' autonomy and social contacts without decreasing time spent with their children (Muller). Because the MIDUS does not include data on whether mothers were employed full time or part time, we focus on the duration in which a mother was employed during one's childhood. In Sugar's (1994) study, the effects of maternal employment on daughters' feeling isolated and their perceptions of lack of warmth at home were particularly evident among those whose mothers worked many years during their childhood. We expect that adults who had employed mothers during all or most of their childhood will report less support, less discipline, and more verbal or physical assaults than adults who had stay-at-home mothers. In contrast, we expect that adults who had employed mothers during some or a little of their childhood will report more support, more discipline, and fewer verbal or physical assaults than adults who had stay-at-home mothers.

We also examine adults' perceptions of their fathers' parenting practices in childhood and whether their perceptions are related to maternal employment status. In general, compared with mothers, fathers are more likely to devote their time to the provider role, to rely on their spouse for daily discipline and supervision of their children, and hence to have less close relationships with their children (Townsend, 2002). Maternal employment may alter family dynamics, and hence, it may affect how fathers relate to their children. It has been found that wives' employment increases men's time spent with their children without their wife present (Richards \& Duckett, 1994) and increases time in housework or personal care of the children rather than playing (Bryant \& Zick, 1996; Yeung, Sandberg, Davis-Kean, \& Hofferth, 2001). Some studies, however, have found little difference in fathers' involvement in child care by their spouses' employment status (e.g., Nock \& Kingston, 1988). How fathers' involvement as caregivers for children is related to their ability to make their children feel supported and well supervised, and not to employ verbal or physical assaults toward their children, is unknown. Role strain perspectives assume that the role of nurturing father may lead men to role overload, especially because taking care of children is more frustrating and time intensive during daily routines than during playtimes. In contrast, role enhancement perspectives suggest that the caregiving role opens up men's parenting opportunities that allow them to learn how to get close to children and supervise them closely. Involvement in daily care of their 
children may let men feel more integrated into family life. The sense of being part of a team may prohibit men from becoming harsh toward their children.

The relationship between maternal employment and adult children's perceptions of their mothers' and fathers' parenting practices during childhood may vary by particular subgroups because of variations in expectations with regard to mothers' roles. In this article, we examine two subgroup differences. First is by birth cohort. In the past several decades, mothers are increasingly staying in the labor force, working more weeks per year, and working more hours per week (Cohen \& Bianchi, 1999). Although it has been a less dramatic change, fathers' involvement in childrearing has increased over time (Bianchi, 2000). Americans' attitudes have shifted to be more favorable toward mothers' employment (Brewster \& Padavic, 2000). Unlike those who were raised in families with employed mothers in the 1950s and the early 1960s, those who grew up in families with employed mothers during and after the feminist movement of the late 1960s lived in a cultural context in which it was more normative for mothers to be employed and where fathers may have adapted to two-earner marriages and have become more involved in children's lives. Thus, children of employed mothers in recent cohorts may report better parenting skills compared with their counterparts who grew up earlier in the 20th century.

The other subgroup difference we examine in this article is by adult child's gender. In general, daughters tend to be more critical evaluators than sons of their relationships with their mothers (Wodak \& Schulz, 1985). Among those with employed mothers, however, daughters seem to be more likely than sons to report higher levels of feeling loved, supported, and understood by mothers (Galinsky, 1999). This may be because differences in parenting practices by mothers' employment status, if any, are greater for sons than for daughters. Some studies have found that boys with employed mothers received less stimulation and responsiveness from parents than girls with employed mothers or than children of either gender in families with stay-at-home mothers (Chase-Lansdale \& Owen, 1987; Stuckey, McGhee, \& Bell, 1982). Mothers who work longer hours are less likely to spend time on the routine care of their children only when they have sons (Goldberg, Greenberger, \& Nagel, 1996). Fathers with employed wives spend about the same amount of time with their sons and daughters, whereas fathers with nonemployed wives spend more time with their sons (Crouter \& Crowley, 1990). Explanations for such gender differences are debatable. Parents may see sons as more difficult to control or more demanding than daughters. This view may make it harder for parents to be warm and less harsh toward sons than daughters when they are under strong time pressures (Bronfenbrenner, Alvarez, \& Henderson, 1984). Parents may view sons as more independent than daughters, and hence, when mothers are consumed by paid work, they may reduce their efforts to interact with sons (ChaseLansdale \& Owen). Maternal employment may be related to couples' attitudes: Couples where the wife is employed probably have less traditional attitudes toward women's and men's family roles, and hence, they may treat sons and daughters more equally, whereas couples where the wife stays at home may pay more attention to sons than to daughters (Crouter \& Crowley).

We limit our investigation to those who had two biological parents present in the household until the age of 16 to eliminate the complexity of the effects of parental separation, residential status, or having a stepparent on children's perceptions of their mothers' and fathers' parenting practices (e.g., Coley, 2003; Thomson, Mosley, Hanson, \& McLanahan, 2001). We include several factors in our analysis as controls. Some mothers may be employed because of their husbands' unemployment; it may be their unemployment, not their wives' employment that leads fathers to poor parenting (Parcel \& Menaghan, 1994). It may be family income rather than maternal employment that reduces financial strains and in turn allows parents to be warmer, more attentive, and less angry toward their children (Desai, Chase-Lansdale, \& Michael, 1989). Parental levels of education may be related to both whether mothers were employed and parenting practices (Bryant \& Zick, 1996; Nock \& Kingston, 1988; Yeung et al., 2001). Mothers with more children are less likely to spend time with each child on a one-on-one basis (Milkie, Mattingly, Nomaguchi, Bianchi, \& Robinson, 2004), and the number of children is related to cohort and whether their mothers are employed. Both prevalence of maternal employment and parenting practices may also be affected by urban/rural residence (Tichamyer, \& Duncan, 1990), immigrant status, and race/ ethnicity (Bulcroft, Carmody, \& Bulcroft, 1996; McLoyd, Cauce, Takeuchi, \& Wilson, 2000). 
On the basis of the foregoing background, we test the following hypotheses:

Hypothesis 1a: On the basis of role strain perspectives, adults whose mothers were employed outside the home during all or most of their childhood will report less support, less discipline, and more verbal or physical assaults by their mother and father compared to those with homemaker mothers.

Hypothesis 1b: On the basis of role enhancement perspectives, adults whose mothers were employed outside the home during some or a little of their childhood will report more support, more discipline, and fewer verbal or physical assaults by their mother and father compared to those with homemaker mothers.

Hypothesis 2: The relationship between maternal employment and adults' perceptions of parenting practices during childhood will vary by birth cohort. Adults in earlier cohorts will be more likely than adults in the most recent cohort to report less support, less discipline, and more physical or verbal assaults when mothers were employed for all or most of their childhood.

Hypothesis 3: The relationship between maternal employment and adults' perceptions of parental practices during childhood will vary by gender. Sons but not daughters whose mothers were employed during all or most of their childhood will report less support, less discipline, and more physical or verbal assaults by their mothers and fathers compared to their counterparts whose mothers stayed at home.

\section{METHOD}

\section{Sample}

Data for this study were drawn from the MIDUS, a national multistage probability sample of noninstitutionalized, English-speaking Americans aged 25 - 74 years, which were collected in 1995 1996 through telephone interview and selfadministered questionnaire (MacArthur Foundation Research Network on Successful Midlife Development, or MIDMAC, 2005). In the first stage, households were selected by random-digit dialing. In the second stage, disproportionate stratified sampling was used to select respondents. Men and persons aged $65-74$ years were oversampled. The response rates for the telephone interview and for the self-administered questionnaire are $70 \%$ and $87 \%$, respectively. The MIDUS sample includes 3,032 adults.

For this study, we selected those who had two biological parents present in the household until the age of 16 and who completed both the telephone interview and the self-administered questionnaire $(n=2,308 ; 76.1 \%)$. We excluded respondents who had missing data on age $(n=$ $21 ; 0.7 \%)$ and the question about their mothers' employment status in childhood $(n=62$; $2.0 \%$ ). Our final sample size is $N=2,246$. All analyses in this study are based on the weighted data. The weight variable adjusts the sample to match the populations of adults in the October 1995 Current Population Survey.

\section{Dependent Variables}

We examined three aspects of parenting practices for mothers and fathers: support, discipline, and verbal or physical assaults. Support by mother/ father was measured by six questions, including (a) "How much did she/he understand your problems and worries?" (b) "How much could you confide in her/his about things that were bothering you?" (c) "How much love and affection did she/he give you?" (d) "How much time and attention did she/he give you when you needed it?" (e) "How much effort did she/ he put into watching over you and making sure you had a good upbringing?" (f) "How much did she/he teach you about life?" $(0=$ not at all, $1=$ a little, $2=$ some, $3=$ a lot ). An index was created by summing the six items for each parent (ranging from 0 to 18). Cronbach's $\alpha$ is .90 for mothers and .92 for fathers, respectively. Discipline by mother/father was measured by following three questions: (a) "How strict was she/he with her/his rules for you?" (b) "How consistent was she/he about her/his rules for you?" (c) "How much did she/he stop you from doing things that other children of your age were allowed to do?" $(0=$ not at all, $1=$ a little, $2=$ some, $3=a$ lot ). An index was created by summing the three items for each parent (ranging from 0 to 9). Cronbach's $\alpha$ is .74 for mothers and .81 for fathers. These two measures have been used in previous studies (e.g., Rossi, 2001). Verbal or physical assaults by mother/ father is measured using the Conflict Tactics Scale that has been widely used to measure physical and psychological aggression of parents 
or spouses (Straus, Hamby, Boney-McCoy, \& Sugarman, 1996). In MIDUS, respondents were asked "During your childhood, how often did your mother/father or the woman/man who raised you do any of the things on List $\mathrm{A} / \mathrm{B} / \mathrm{C}$ to you?" List A includes verbal and emotional assaults including "insulted you or swore at you; sulked or refused to talk to you; stomped out of the room; did or said something to spite you; threatened to hit you; and smashed or kicked something in anger." List B includes physical assaults such as "pushed, grabbed, or shoved you; slapped you; threw something at you." List C includes severe physical abuse such as "kicked, bit, or hit you with a fist; hit or tried to hit you with something; beat you up; choked you; burned or scalded you." The response category for each item includes $0=$ never, $1=$ rarely, $2=$ sometimes, and $3=$ often. Then three items were summed to create a scale (ranging from 0 to 9). Cronbach's $\alpha$ is .80 for mothers and .83 for fathers.

\section{Independent Variables}

Maternal employment in childhood was measured by the question, "Other than being a housewife, how much of your childhood did your mother either work for pay or work in a family business?" $(1=$ all, $2=$ most, $3=$ some, $4=$ a little, or $5=$ not at all). We created a categorical variable indicating whether respondents' mother was employed (a) all or most, (b) some or a little, or (c) not at all during their childhood. In multivariate analyses, we created three dummy variables and used the not at all category. We examined different cutpoints of categories with similar results to those reported here. Gender is measured as a dichotomous variable, labeled Daughters, where women are coded as 1 and men as 0. Birth cohort is a categorical variable that includes (a) Great Depression cohort (born between 1921 and 1930, aged $65-74$ years in 1995); (b) preWorld War II cohort (born between 1931 and 1944, aged 51 - 64 years in 1995); (c) Baby Boom cohort (born between 1945 and 1959, aged 36 - 50 years in 1995); and (d) Baby Bust cohort (born between 1960 and 1970, aged 25 35 years in 1995). Although cutpoints of cohorts are debatable, these groups have been used in other research (e.g., Carr, 2002). In multivariate analyses, we created four dummy variables and used the Baby Bust cohort as the reference group.

\section{Control Variables}

Father's unemployment was measured by the question, "How much of your childhood did your father either work for pay or work in a family business?" The response choice includes (a) all, (b) most, (c) some, (d) a little, or (e) not at all. We created a dichotomous variable where those who answered all were assigned 0s and others were 1s. Perceived financial condition was measured by the question, "When you were growing up, was your family better off or worse off financially than the average family was at that time?" We created a categorical variable that included (a) better off, (b) same as average family, (c) worse off, and (d) missing. For regression analyses, we created four dummy variables, and we used those who answered same as average family as the reference group. Mother's and father's levels of education are categorical variables that indicate the highest grade of school or year of college respondent's mother/father completed, including (a) less than high school, (b) graduated high school, (c) some college education, and (d) bachelor's degree or more. About $8 \%$ of respondents had missing values for mother's and for father's education, and they were included in the modal category, graduated high school. Those who had missing values showed little difference from those who graduated high school in their relationships with parenting practices. In regression analyses, those who graduated high school were used as the reference group.

Number of older siblings, which refers to biological, step-, or half-brothers and sisters, is a categorical variable including (a) none, (b) one, or (c) two or more. Number of younger siblings (including siblings of the same age) was created in the same way. In regression analyses, none was used as the reference group. Urban/ rural residence was measured by the question, "Which of the following best describes the areas where you were raised during most of your childhood?" The response choice includes (a) rural, (b) small town, (c) medium-sized town, (d) suburbs, (e) city, and (f) moved around. For regression analyses, we created six dummy variables, and we used those who grew up in medium-sized towns as the reference group. Parents' immigration status was measured by the questions, "Was your mother/ father born in the United States?" We created a dichotomous variable: Respondents with both 
parents born in the United States were assigned $1 \mathrm{~s}$, and others 0s. Respondent's racelethnicity is a categorical variable created based on two questions. First, respondents were asked, "Other than being American, what are your main ethnic origins? That is, what countries or continents are your ancestors from?" Those who said that their ancestors were from Spanish- or Portuguese-speaking countries in North, Central, or South America such as Mexico or Puerto Rico were counted as Hispanic. We used an additional question, "What race do you consider yourself to be?" The response choices included (a) White, (b) Black and/or African American, (c) Native American or Aleutian Islander/Eskimo, (d) Asian or Pacific Islander, (e) other, and (f) multiracial. From these two questions, we created the categories (a) nonHispanic White, (b) non-Hispanic Black, (c) Hispanic, (d) other race, and (e) no answer. In regression analyses, we created dummy variables, and non-Hispanic White was used as the reference group.

\section{Analysis Plan}

We use OLS (ordinary least square) regression models to test our hypotheses. First, we examine the relationship between maternal employment status in childhood and adults' perceptions of their mothers' and fathers' parenting practices during childhood, controlling for variables such as fathers' unemployment, economic conditions, the number of children in the household, and so forth. This main effects model tests Hypothesis $1 \mathrm{a}$ and $1 \mathrm{~b}$. Second, we examine cohort differences by adding interaction terms between maternal employment status in childhood and birth cohort to the main effects model (Hypothesis 2). Third, we examine gender differences by adding interaction terms between maternal employment in childhood and respondents' gender to the main effects model (Hypothesis 3). We present results for mothers' parenting first, followed by results for fathers' parenting.

\section{RESULTS}

\section{Descriptive Statistics}

Table 1 shows descriptive statistics for variables for the total sample and by maternal employment status in childhood. About $38 \%$ of respondents reported that their mother stayed at home during all of their childhood; about $35 \%$ reported that their mother was employed during some or a little of their childhood; and 27\% reported that their mother was employed during all or most of their childhood. We used two-tailed $t$ tests to examine whether the differences in means of each variable in the analysis are statistically significant for those whose mothers were employed during some or a little of their childhood and for those whose mothers were employed during all or most of their childhood, respectively, compared with those who had stay-at-home mothers.

At the bivariate level, there is little difference in adults' reports of their mothers' support and verbal or physical assaults in childhood by their mothers' employment status. Those whose mothers worked outside the home, however, regardless of the years of employment, reported less maternal discipline compared with those whose mothers did not work outside the home at all. More differences are observed in fathers' perceived parenting. Adults whose mothers worked for pay during all or most of their childhood reported less support, less discipline, and more verbal or physical assaults by their fathers during childhood compared with those who had homemaker mothers. Adults whose mothers were employed during some or a little of their childhood also reported a lower level of support from their fathers in childhood than those whose mothers stayed at home.

\section{Maternal Employment in Childhood and Adults' Reports of Mothers' Parenting Practices}

Table 2 shows results from multivariate analyses for adults' perceptions of mothers' parenting practices during their childhood, in terms of perceived support, discipline, and verbal or physical assaults. We examined three models for each dependent variable. Model 1 examines the relationship between maternal employment and adults' reports of mothers' parenting practices during their childhood, controlling for other variables, to test Hypotheses 1a and 1b. Model 2 adds interaction terms of Birth Cohort $\times$ Maternal Employment to test Hypothesis 2, whether the relationships vary by birth cohorts. Model 3 adds interaction terms of Gender $\times$ Maternal Employment to test Hypothesis 3, whether the relationships vary by gender. Note that the number of cases varies because of missing data on the dependent variables. 
Table 1. Weighted Means (Standard Deviations) and Percentage Distribution for Variables in Analyses for Total Sample and by Maternal Employment Status in Childhood $(\mathrm{N}=2,246)$

\begin{tabular}{|c|c|c|c|c|}
\hline & \multirow[b]{2}{*}{ Total Sample } & \multicolumn{3}{|c|}{ Mother's Employment Status in Childhood } \\
\hline & & $\begin{array}{c}\text { Homemaker } \\
\text { Mothers }(37.5 \%)\end{array}$ & $\begin{array}{c}\text { Employed } \\
\text { Some or A } \\
\text { Little of } \\
\text { Childhood } \\
(35.2 \%)\end{array}$ & $\begin{array}{c}\text { Employed All } \\
\text { or Most of } \\
\text { Childhood } \\
(27.3 \%)\end{array}$ \\
\hline \multicolumn{5}{|l|}{ Perceived mother's parenting practices $(M)$} \\
\hline Support $(0-18)$ & $13.5(4.0)$ & $13.6(3.9)$ & $13.4(4.0)$ & $13.3(4.1)$ \\
\hline Discipline $(0-9)$ & $6.3(1.9)$ & $6.4(1.9)$ & $6.2(1.9)^{*}$ & $6.2(1.9)^{*}$ \\
\hline Verbal or physical assaults $(0-9)$ & $1.6(1.9)$ & $1.6(1.9)$ & $1.7(1.9)$ & $1.7(2.0)$ \\
\hline \multicolumn{5}{|l|}{ Perceived father's parenting practices $(M)$} \\
\hline Support $(0-18)$ & $11.2(4.7)$ & $11.7(4.5)$ & $11.1(4.7)^{*}$ & $10.7(5.0)^{* * *}$ \\
\hline Discipline $(0-9)$ & $6.1(2.3)$ & $6.2(2.3)$ & $6.1(2.2)$ & $5.8(2.4)^{* * *}$ \\
\hline Verbal or physical assaults $(0-9)$ & $1.9(2.1)$ & $1.7(2.1)$ & $1.9(2.0)$ & $2.0(2.2)^{* *}$ \\
\hline \multicolumn{5}{|l|}{ Birth cohort $(\%)$} \\
\hline Baby Bust (age 25 - 35 years in 1995) & 26.9 & 17.8 & $30.1 * * *$ & $35.3 * * *$ \\
\hline Baby Boom (age $36-50$ years in 1995) & 39.1 & 38.2 & 39.2 & 40.1 \\
\hline Before World War II (age 51 - 64 years in 1995) & 22.1 & 26.3 & $21.0 *$ & $17.9 * * *$ \\
\hline Great Depression (age $65-74$ years in 1995) & 11.9 & 17.7 & $9.7 * * *$ & $6.7 * * *$ \\
\hline \multicolumn{5}{|l|}{ Gender $(\%)$} \\
\hline Daughters & 54.3 & 55.6 & 54.9 & 51.8 \\
\hline Sons & 45.7 & 44.4 & 45.1 & 48.2 \\
\hline \multicolumn{5}{|l|}{ Father's employment status in childhood (\%) } \\
\hline Father was not always employed & 9.7 & 10.1 & 10.4 & 8.3 \\
\hline Father was always employed & 90.3 & 89.9 & 89.6 & 91.7 \\
\hline \multicolumn{5}{|l|}{ Perceived financial conditions in childhood (\%) } \\
\hline Better off & 29.5 & 27.9 & 30.8 & 30.1 \\
\hline Average & 45.3 & 44.1 & 45.9 & 46.3 \\
\hline Worse & 24.1 & 27.0 & $22.4 *$ & $22.4^{*}$ \\
\hline Missing & 1.0 & 1.0 & 0.9 & 1.2 \\
\hline \multicolumn{5}{|l|}{ Mother's education (\%) } \\
\hline College degree & 10.0 & 6.5 & 8.8 & $16.3^{* * *}$ \\
\hline Some college & 11.2 & 9.5 & 12.4 & 11.8 \\
\hline High school & 43.5 & 44.0 & 46.1 & 39.6 \\
\hline Less than high school & 35.3 & 39.9 & $32.7 * *$ & $32.3^{* *}$ \\
\hline \multicolumn{5}{|l|}{ Father's education (\%) } \\
\hline College degree & 14.5 & 13.5 & 16.5 & 13.3 \\
\hline Some college & 9.2 & 8.2 & 9.4 & 10.2 \\
\hline High school & 35.6 & 35.0 & 36.8 & 34.8 \\
\hline Less than high school & 40.7 & 43.3 & $37.3^{*}$ & 41.7 \\
\hline \multicolumn{5}{|l|}{ Older siblings $(\%)$} \\
\hline None & 32.5 & 29.2 & 33.1 & $36.3 * *$ \\
\hline One & 25.3 & 25.2 & 26.6 & 23.7 \\
\hline Two or more & 42.2 & 45.6 & $40.3 *$ & $39.9 *$ \\
\hline \multicolumn{5}{|l|}{ Younger siblings (\%) } \\
\hline None & 30.0 & 28.1 & 28.4 & $34.6^{* *}$ \\
\hline One & 27.8 & 24.6 & $30.4 * *$ & 29.0 \\
\hline Two or more & 42.2 & 47.3 & $41.2^{*}$ & $36.4 * * *$ \\
\hline
\end{tabular}


Table 1. Continued

\begin{tabular}{|c|c|c|c|c|}
\hline & \multirow[b]{2}{*}{ Total Sample } & \multicolumn{3}{|c|}{ Mother's Employment Status in Childhood } \\
\hline & & $\begin{array}{c}\text { Homemaker } \\
\text { Mothers }(37.5 \%)\end{array}$ & $\begin{array}{c}\text { Employed } \\
\text { Some or A } \\
\text { Little of } \\
\text { Childhood } \\
(35.2 \%)\end{array}$ & $\begin{array}{c}\text { Employed All } \\
\text { or Most of } \\
\text { Childhood } \\
(27.3 \%)\end{array}$ \\
\hline \multicolumn{5}{|l|}{ Urban/rural residence in childhood (\%) } \\
\hline Rural area & 25.0 & 28.7 & $20.9 * * *$ & 25.2 \\
\hline Small town & 26.5 & 23.9 & $28.9 *$ & 26.9 \\
\hline Middle-size town & 11.2 & 10.4 & 10.9 & 12.9 \\
\hline Suburbs & 15.5 & 14.1 & 17.4 & 15.1 \\
\hline City & 18.2 & 19.4 & 17.8 & 16.8 \\
\hline Moved around & 3.6 & 3.5 & 4.1 & 3.1 \\
\hline \multicolumn{5}{|l|}{ Immigrant status $(\%)$} \\
\hline Both parents were born in United States & 86.6 & 84.2 & $87.6^{*}$ & $88.8 *$ \\
\hline Either parent was born outside the United States & 13.4 & 15.8 & 12.4 & 11.2 \\
\hline \multicolumn{5}{|l|}{ Race/ethnicity $(\%)$} \\
\hline White & 83.4 & 84.3 & 86.7 & $78.0 * *$ \\
\hline Black & 8.4 & 7.3 & 6.1 & $13.0 * * *$ \\
\hline Hispanic & 2.9 & 2.7 & 3.0 & 2.8 \\
\hline Other race & 3.1 & 3.6 & $1.7 *$ & 4.2 \\
\hline Missing & 2.2 & 2.0 & 2.5 & 1.9 \\
\hline
\end{tabular}

Note: Percentages may not add to $100 \%$ because of rounding. Ns for dependent variables vary because of missing data (see Tables 2 and 3). Differences from those with homemaker mother are significant at $* p<.05$, ** $p<.01$, *** $p<.001$ (twotailed $t$ tests).

Table 2 shows that adults whose mothers worked for pay during all or most of their childhood reported a lower level of maternal support during childhood compared with those whose mothers stayed at home (Model $1, b=-.48$, $p<.05$ ). Adults who had employed mothers during some or a little of their childhood do not differ from those who had homemaker mothers in their perceptions of maternal support in childhood. These results do not vary by birth cohort (Model 2) and do not vary by gender (Model 3). For mothers' discipline, similar patterns were found. Adult children who had employed mothers during all or most of their childhood reported a lower level of discipline by their mothers than those who had homemaker mothers (Model 1, $b=-.24, p<.05$ ). Those who had employed mothers during some or a little of their childhood do not differ from those who had homemaker mothers in their perceptions of maternal discipline in childhood. These findings do not vary by cohort (Model 2) and do not vary by gender (Model 3).
The relationship between maternal employment status and adults' reports of their mothers' verbal or physical assaults during childhood shows different patterns. Mothers' employment status is not related to mothers' verbal or physical assaults (Model 1), and this does not vary by birth cohort (Model 2). There is a gender difference, however. In Model 3, the interaction effect of Gender $\times$ Maternal employment during all or most of childhood on verbal or physical assaults is statistically significant and negative $(b=-.47$, $p<.05)$. To interpret this interaction effect, we calculated adjusted means of adults' perceptions of verbal or physical assaults by mothers during childhood for six subgroups by gender and maternal employment status. The results are shown in Figure 1. Daughters show little difference in their perceptions of their mothers' verbal or physical assaults in childhood by mothers' employment status in childhood. In contrast, sons' perceptions of their mothers' verbal or physical assaults vary between those whose mothers were employed and those whose 


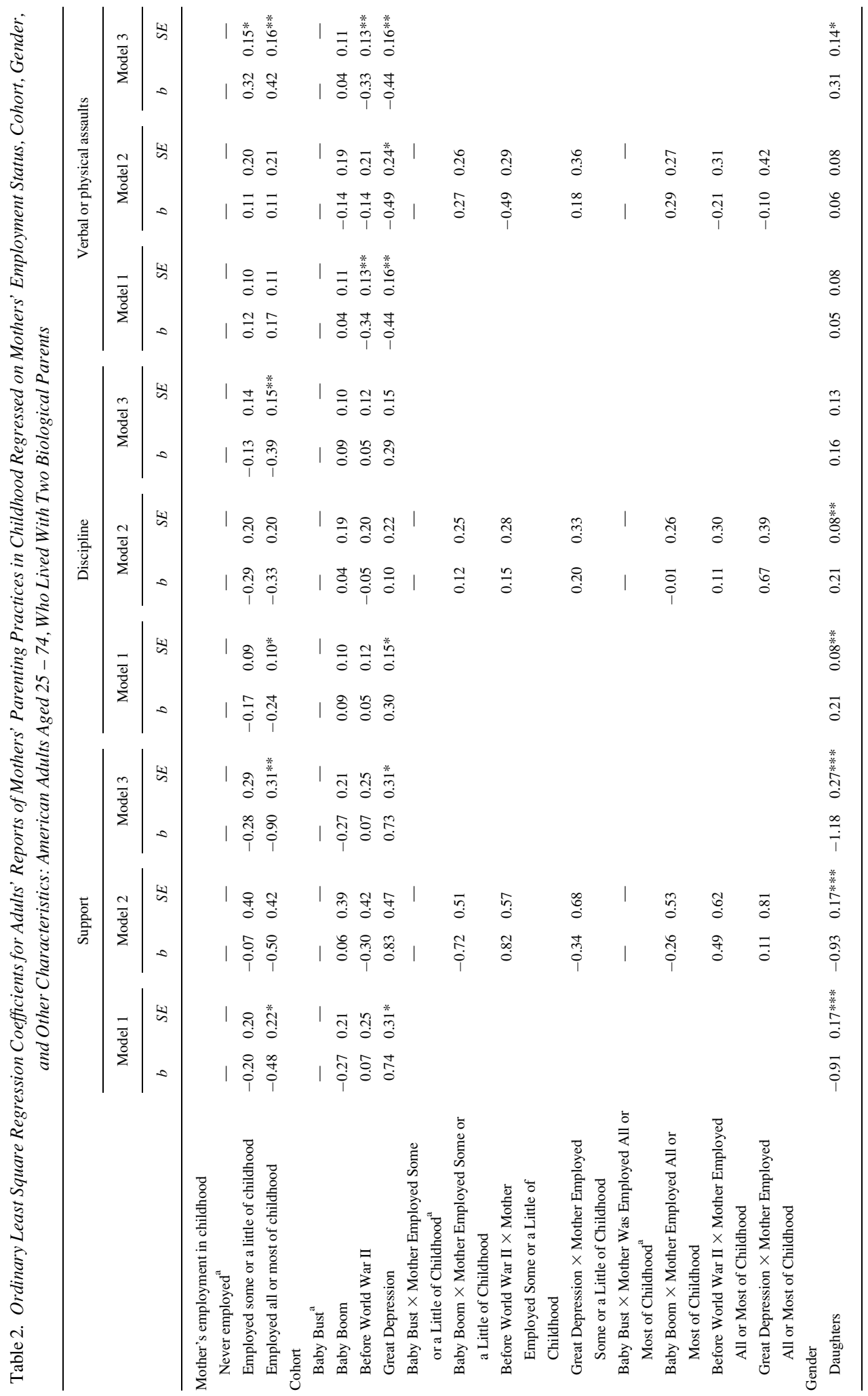




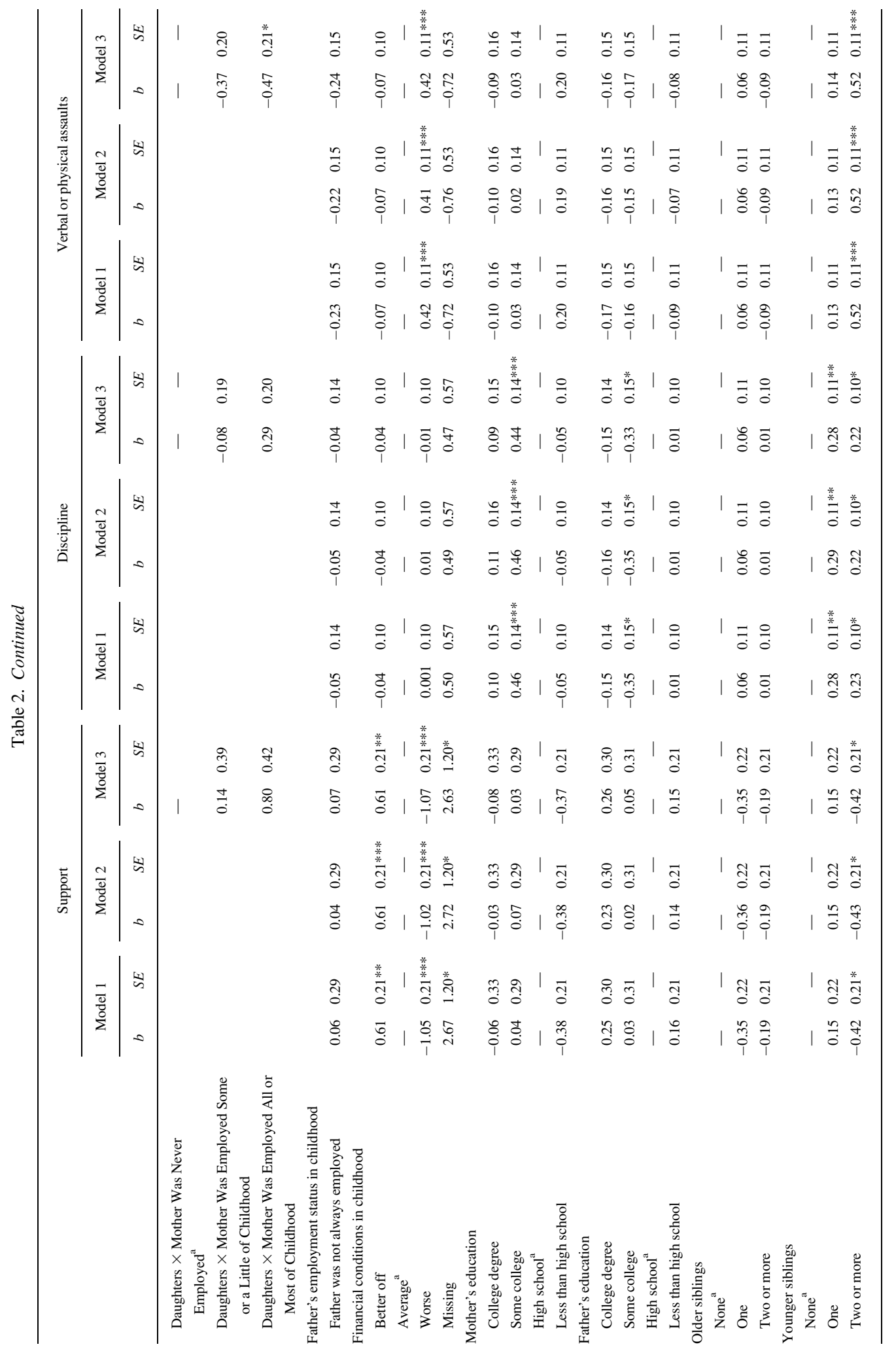




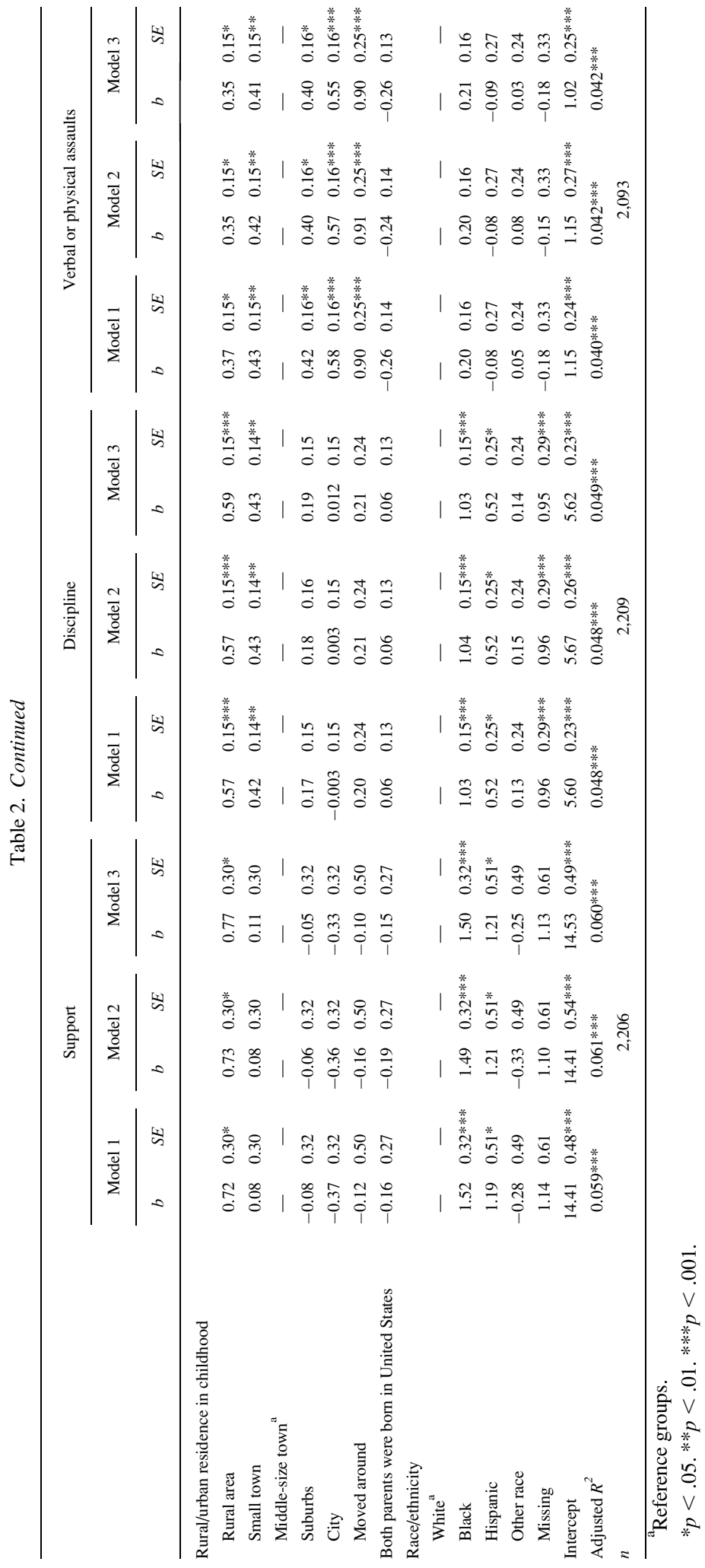


Figure 1. AdJUSTED MEANS OF AdUlts' PERCEPTIONS OF VERbAL OR PHYSICAL ASSAULTS By MOTHER IN CHILDHOOD BY GENDER AND MATERNAL EMPLOYMENT IN CHILDHOOD

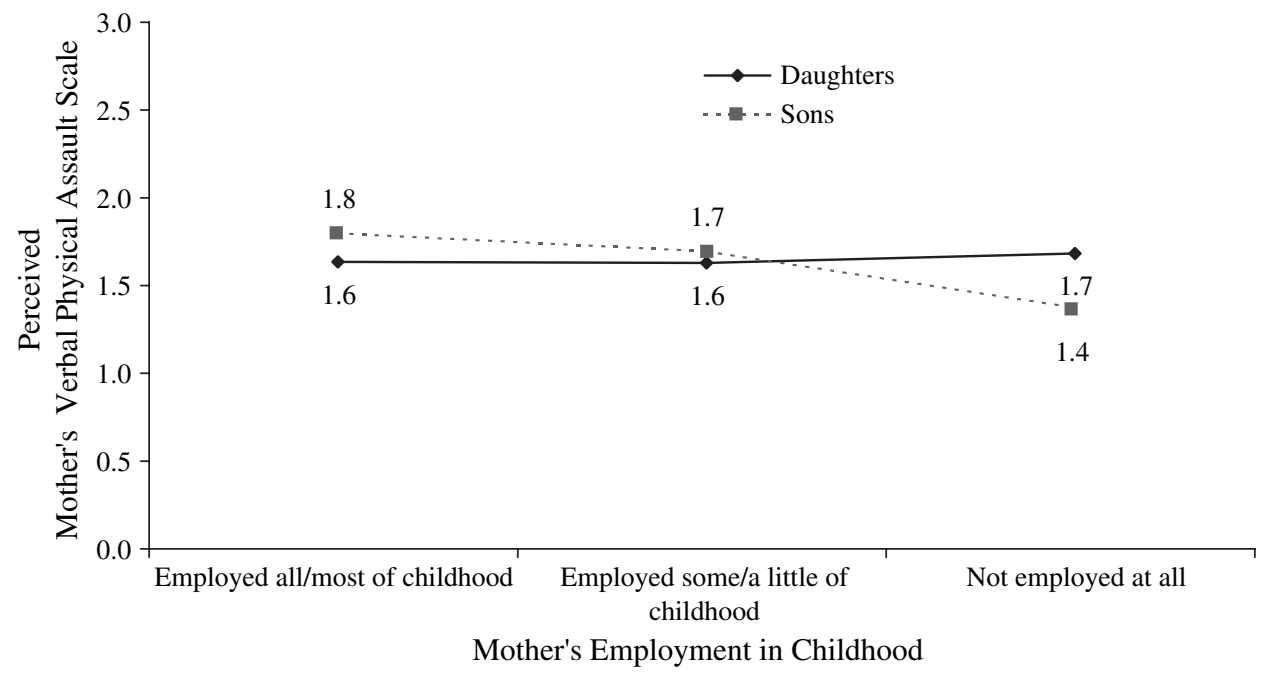

Note: Adjusted means were calculated by using unstandardized coefficients from the regression Model 3 of Table 2, which controls for birth cohort, father's employment status in childhood, financial conditions in childhood, mother's and father's education, the number of older siblings, the number of younger siblings, rural/urban residence in childhood, parents' immigration status, and race/ethnicity.

mothers were not employed. Sons who reported that their mothers were not employed at all during their childhood reported a lower level of mothers' verbal or physical assaults in childhood than both sons whose mothers were employed during some or a little of their childhood and sons whose mothers were employed during most or all of their childhood.

\section{Maternal Employment in Childhood and Adults' Reports of Fathers' Parenting Practices}

Do adults' perceptions of their fathers' parenting practices in childhood vary by their mothers' employment status in childhood? Table 3 shows results from the same set of regression models for fathers' parenting. With regard to adults' perceptions of support from their fathers during childhood, as seen for perceptions about their mothers, those whose mothers worked outside the home during all or most of childhood reported a lower level of support from their fathers compared with those whose mother stayed at home (Model $1, b=-1.02, p<.001$ ). Adults who had employed mothers during some or a little of their childhood also reported a lower level of support from their fathers than adults who had homemaker mothers $(b=-.56, p<.05)$. These findings vary neither by birth cohort (Model 2) nor by gender (Model 3).

Adults whose mothers were employed during all or most of their childhood reported a lower level of discipline by their fathers compared with those whose mother stayed at home (Model 1, $b=-.41, p<.01)$. Adults who had employed mothers during some or a little of their childhood did not differ from those who had homemaker mothers in their perceptions of fathers' discipline in childhood. No interaction effects, either for birth cohort or for gender, were significant (Models 2 and 3).

With regard to fathers' verbal or physical assaults, adults who had employed mothers during all or most of their childhood were more likely to report such incidents by their fathers compared with those whose mothers stayed at home (Model $1, b=.29, p<.05)$. Adults who had employed mothers during some or a little of their childhood did not differ from those who had homemaker mothers in their reports of verbal or physical assaults by their fathers during 


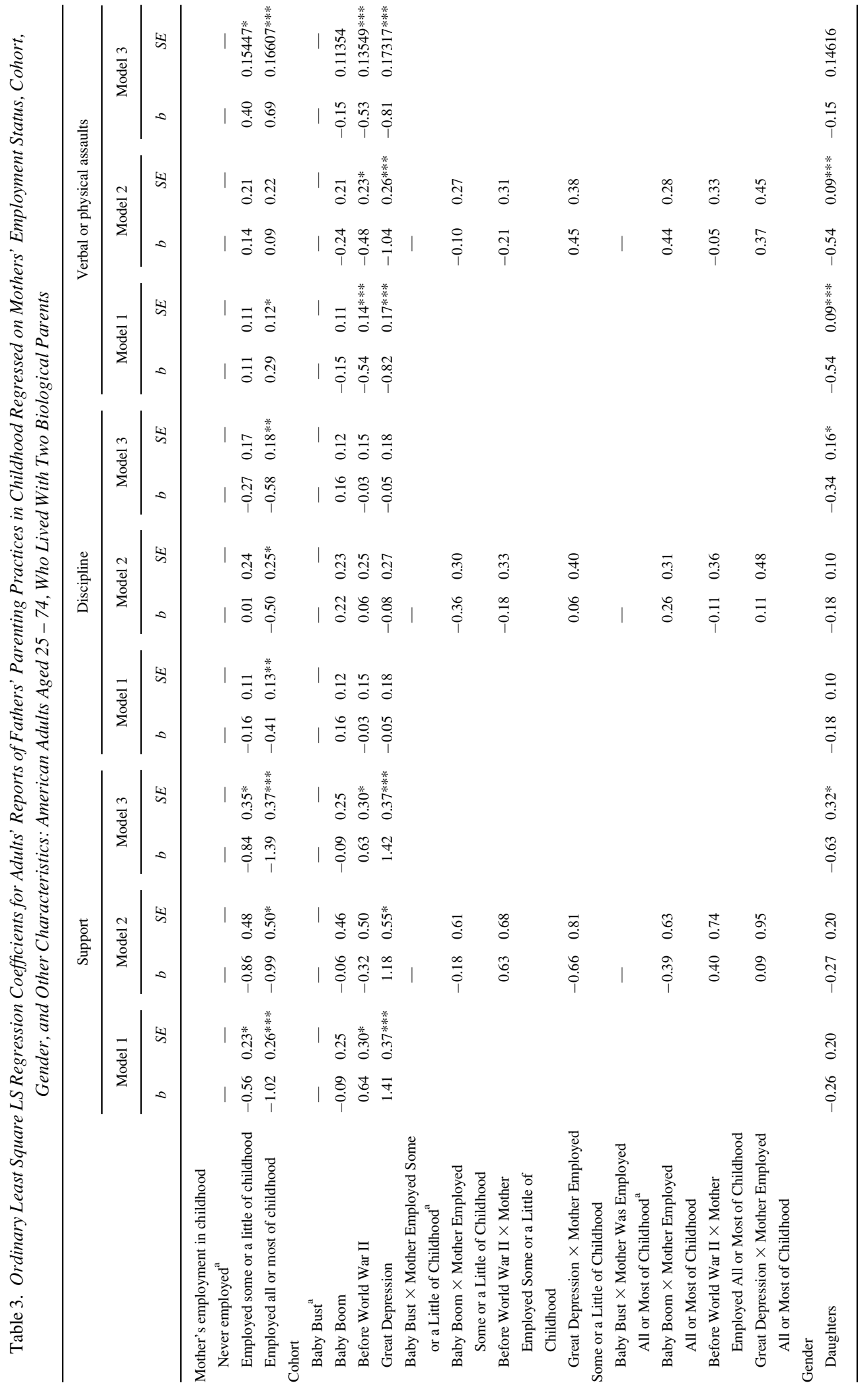




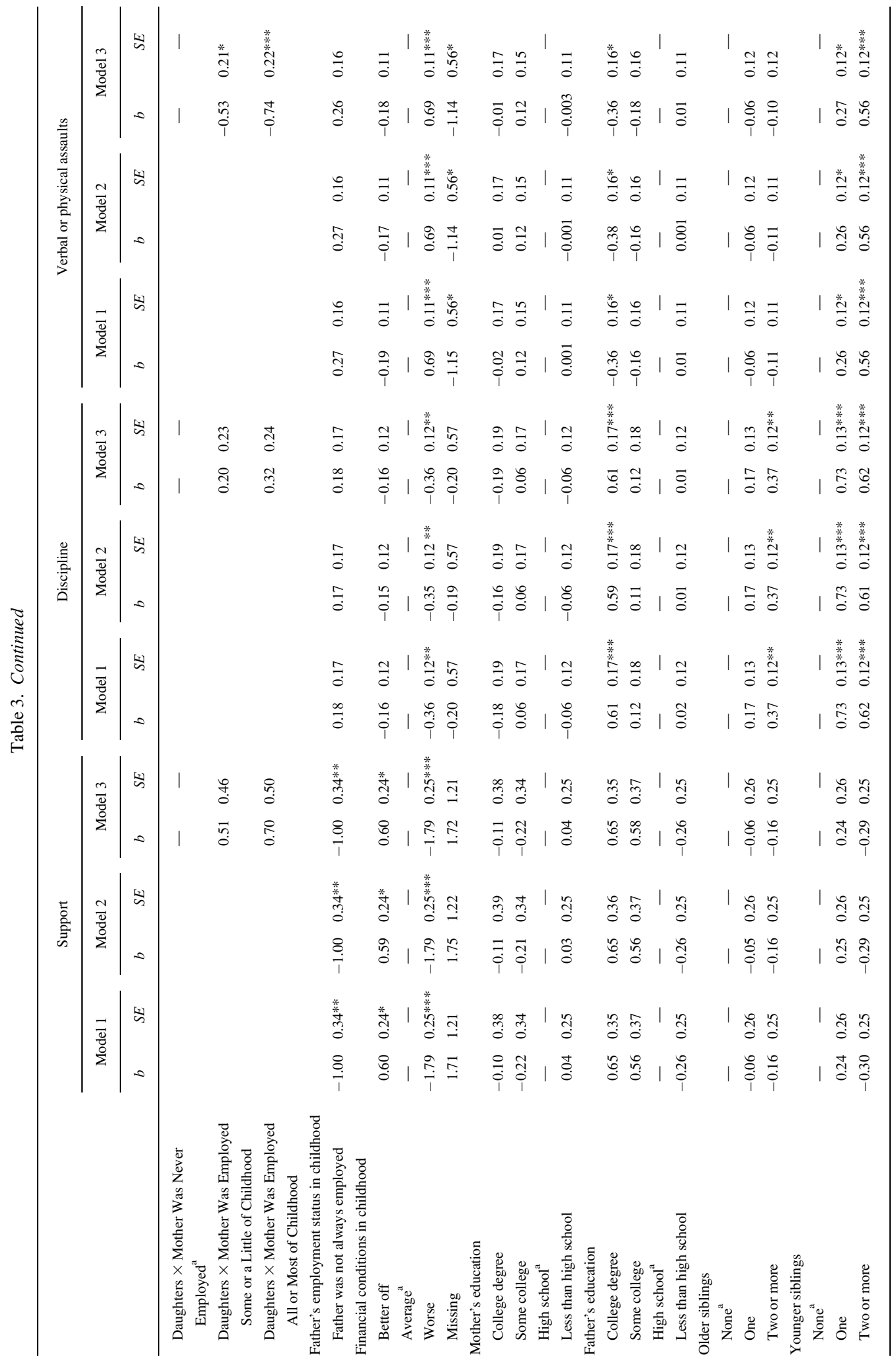




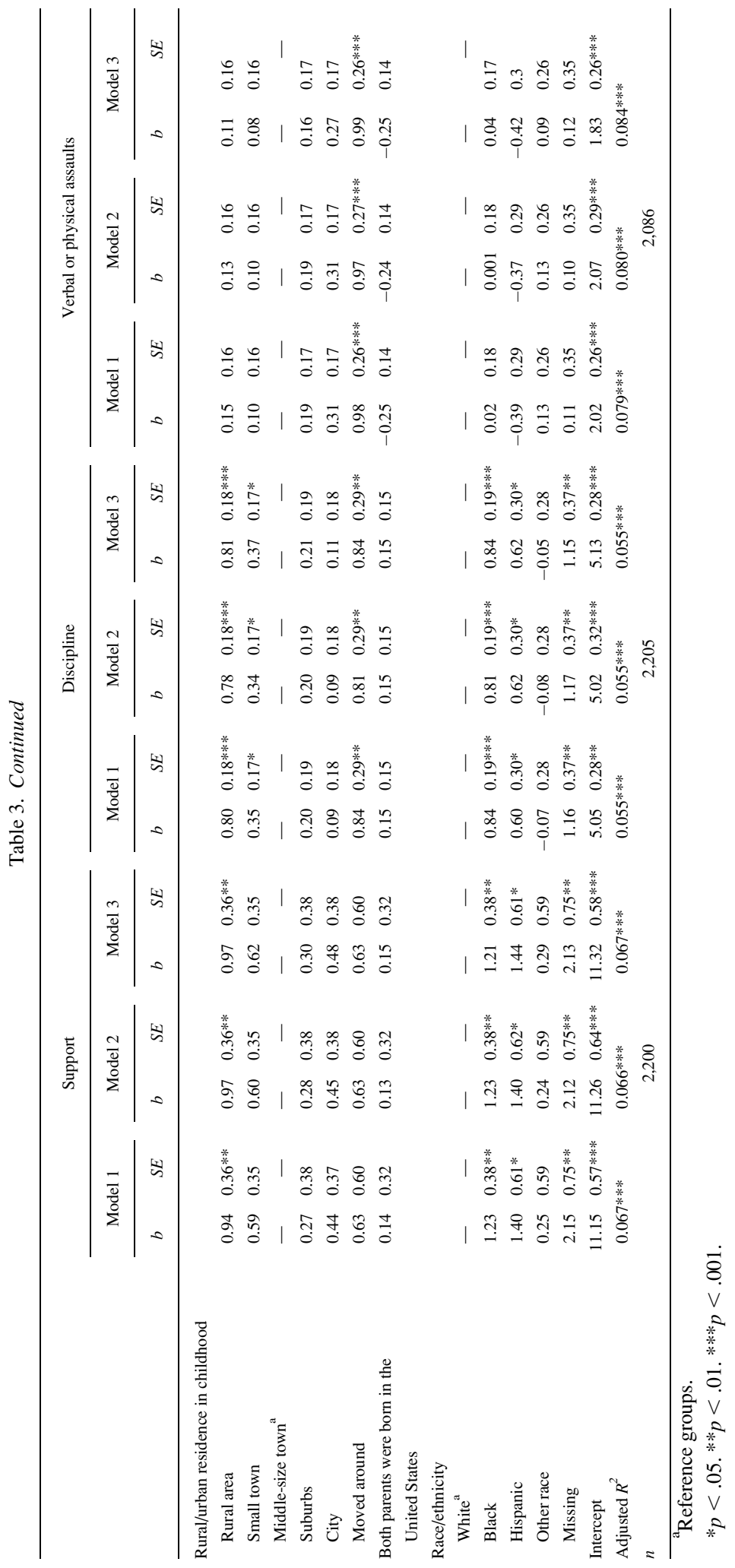


childhood. These findings did not vary by birth cohort (Model 2). They vary by gender, however. In Model 3, the coefficients for Gender $\times$ Maternal Employment during all or most of their childhood $(b=-.74, p<.001)$ and for Gender $\times$ Maternal Employment during some or a little of their childhood $(b=-.53, p<$ $.05)$ are statistically significant, and the signs are negative. To interpret these gender interactions, we calculated adjusted means of adults' perceptions of their fathers' verbal or physical assault in childhood by mothers' employment status for daughters and sons. The results are shown in Figure 2. Daughters show little difference in their reports of their fathers' verbal or physical assaults in childhood by their mothers' employment status during childhood. On the contrary, sons' reports vary by their mothers' employment status. Sons who reported that their mothers were employed during all or most of their childhood reported the highest level of fathers' verbal and physical assaults, whereas sons who reported that their mothers stayed at home throughout their childhood reported the lowest level of fathers' verbal and physical assaults. Sons who reported that their mothers were employed during some or a little of their childhood reported a lower level of fathers' verbal and physical assaults than sons whose mothers were employed during all or most of their childhood but a higher level than sons whose mothers stayed at home.

\section{Summary}

In sum, our findings showed that adults who had employed mothers during all or most of their childhood reported less support and less discipline by both mothers and fathers in their childhood compared with adults who had stay-athome mothers. Hypothesis 1a was supported. Adults who had employed mothers during some or a little of their childhood showed little difference from those who had homemaker mothers throughout their childhood in perceived support, discipline, or verbal or physical assaults by parents, with some exceptions in fathers' parenting. Compared with their counterparts whose mothers stayed at home throughout their childhood, both daughters and sons whose mothers were employed during some or a little of their childhood reported lower levels of support by their fathers, and sons also reported higher levels of fathers' verbal or physical assaults. Hypothesis $1 \mathrm{~b}$ was

Figure 2. AdJUSTEd MEANS OF AdUlts' PERCEPTIONS OF VERbAl OR PHYSICAL ASSAULTS By FATHER IN CHILDHOOD BY GENDER AND MATERNAL EMPLOYMENT IN CHILDHOOD

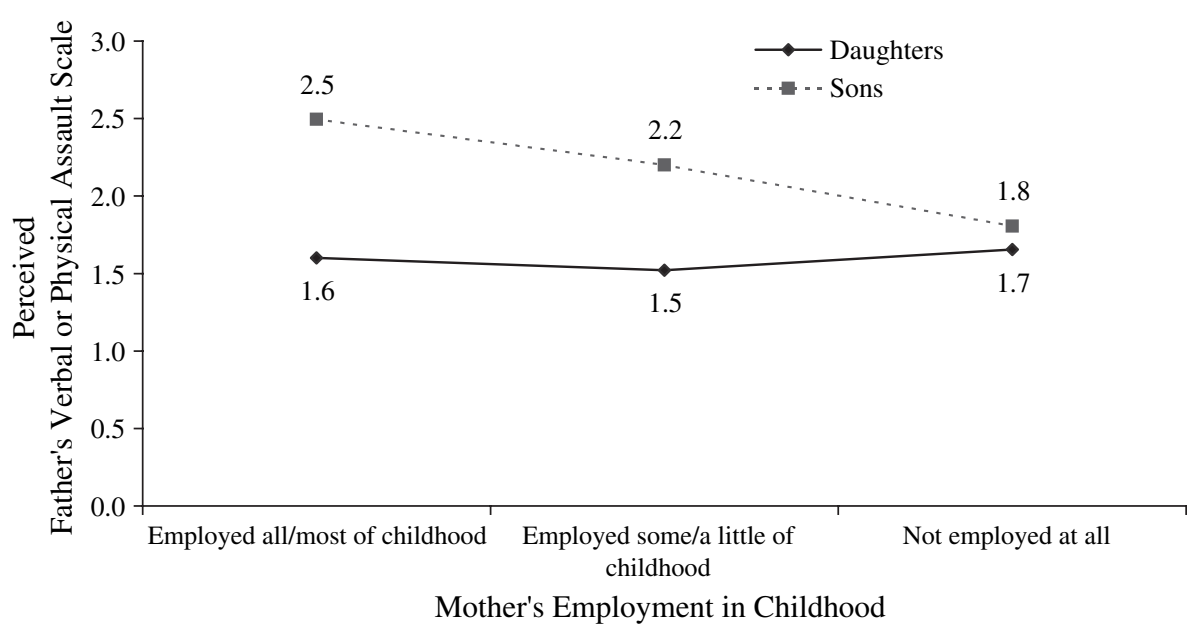

Note: Adjusted means were calculated by using unstandardized coefficients from the regression Model 3 of Table 3, which controls for birth cohort, father's employment status in childhood, financial conditions in childhood, mother's and father's education, the number of older siblings, the number of younger siblings, rural/urban residence in childhood, parents' immigration status, and race/ethnicity. 
not supported. Contrary to our prediction, we found no differences across four cohorts in the relationships between maternal employment and adults' reports on their mothers' and fathers' parenting practices. Hypothesis 2 was not supported. Finally, gender differences in the relationship between maternal employment and mothers' and fathers' parenting practices were found in terms of verbal or physical assaults only. Daughters showed little difference in their reports of fathers' verbal or physical assaults by their mothers' employment status. In contrast, sons whose mothers stayed at home reported a lower level of mothers' verbal or physical assaults during childhood compared with sons whose mothers were employed outside the home. Sons whose mothers worked outside the home, compared with those with homemaker mothers, regardless of the length of their mothers' employment, were more likely to report verbal or physical assaults by their fathers. Hypothesis 3 was supported in terms of parents' verbal or physical assaults but not for support and discipline.

\section{The Effects of Current Social Roles}

One analytic issue that deserves attention is whether experiences in adult lives have any influences on adults' retrospective reports of early-life experiences. It is possible that adults' retrospective reports are colored by present circumstances, such as marriage, parenthood, and employment (Amato, 1991; Roberts \& Bengtson, 1993; Scott \& Alwin, 1998). We did supplemental analyses using the same regression models, controlling for key present-day social statuses, including marital status, levels of education, and employment status. Results regarding the relationship between maternal employment in childhood and children's reports of their mothers' and fathers' parenting practices did not change (data not shown). It has been suggested that adults' retrospective reports of their childhood might be influenced by their current psychological well-being; for example, adults with higher depressive symptoms might recall more unpleasant childhood events than other adults (Amato, 1991). Our results did not change even when we included depression in the regression models (data not shown). Current parent-child relationships might affect adults' perceptions of their parents' behaviors in the past, although the causal direction is debatable (Bedford, 1992). Adults who currently have poor relationships with their parents might recall more negative information about their parents' behaviors in the past than adults who currently have good relationships with their parents. The MIDUS, however, did not ask respondents about their current relationships with their mothers and fathers.

\section{DISCUSSION AND CONCLUSION}

As labor force participation rates for married women with children have risen, the consequences of maternal employment on children's lives have been debated. Some emphasize strain perspectives, arguing that employment may prevent mothers from engaging in sound parenting practices (e.g., warm support, consistent discipline, and little or no harshness) and that the absence of a homemaker may also lead fathers to be less effective in parenting. Others suggest enhancement perspectives, arguing that maternal employment brings new resources and greater opportunities to families, from which both mothers and fathers can benefit and then do a better job in parenting. Although there have been many studies in this area of research, relatively little attention has been paid to how children perceive their relationships with their mothers and fathers and how their views may be influenced by their mothers' employment status. Drawing on the life course perspective, which asserts that children carry their childhood experiences into adulthood (Elder \& Johnson, 2002; Rossi \& Rossi, 1990), this study sought to examine the relationship between maternal employment in childhood and adults' retrospective accounts of their mothers' and fathers' parenting practices using a representative national sample of Americans in early to late adulthood. We paid special attention to subgroup variations by birth cohort and gender of the respondents.

Our findings support the role strain perspective more than the role enhancement perspective. Adults whose mothers worked for pay during all or most of their childhood reported lower levels of maternal and paternal support and discipline in their childhood. With a few exceptions, those adults whose mothers worked outside the home during some or a little of their childhood did not show many differences in their perceptions of their mothers' and fathers' parenting practices compared with those who had homemaker mothers during all or most of their childhood. The exceptions were in fathers' support for both daughters and sons and fathers' verbal 
or physical assaults for sons. The interpretation of these results may be debatable. Lower levels of parental support and discipline felt by children of working mothers may reflect different childrearing orientations between employed and nonemployed parents (Hoffman \& Youngblade, 1999). Children in families with employed mothers may be given more independence and autonomy at earlier ages than those in families with stay-at-home mothers. Some research has reported that children of employed mothers feel more privileged in terms of independence and autonomy than their peers who have homemaker mothers (Trimberger \& MacLean, 1982).

We found gender difference only for one measure of parenting: verbal or physical assaults. Maternal employment in childhood was related to adults' perceptions of more verbal or physical assaults by both mothers and fathers only among sons. This finding matches previous studies that indicate that the effects of maternal employment on parenting depend on the child's gender (e.g., Goldberg et al., 1996). Because of data limitations, we were unable to investigate explanations about why sons, but not daughters, experience harsher parenting when their mothers are employed. Other research indicates that boys are in general more likely than girls to be subject to corporal punishment (McLoyd \& Smith, 2002), probably because of parents' gender attitudes. When both parents are employed, job stress and marital conflict may increase the occasions when mothers and fathers get frustrated by their children's misbehaviors and when they may respond to their children harshly. Future research should continue to investigate the role of gender in this area.

Unexpectedly, we did not find any cohort differences. The youngest generation in our sample, Baby Bust men and women, were born between 1960 and 1970 and grew up in the period from the 1960 s to the mid-1980s when, as rates of maternal employment increased rapidly, Americans' attitudes toward working mothers and egalitarian marriage became more favorable (Brewster \& Padavic, 2000). Because of the increase in social acceptance of maternal employment, we expected that, compared with earlier cohorts, the youngest generation might show different relationships between maternal employment and children's perceptions of their mothers' and fathers' parenting practices. One possibility is that, despite the increase in maternal employment, institutional support for working parents in combining work and family life has remained scarce (Glass, 2000). Hence, the difficulty and stressfulness of dual-earner arrangements and their consequences on parent-child relationships may not have been different for those in earlier birth cohorts compared with more recent ones.

We recognize several limitations in this study. First, we examined adults' retrospective reports of their mothers' employment status and their mothers' and fathers' parenting behaviors in their childhood. It would be ideal if we had objective data on maternal employment in childhood and if we examined whether and how the relationship between maternal employment and parenting practices varies when maternal employment was measured by both objective data and children's perceptions. It also would be interesting if we could examine whether the relationship between maternal employment and children's perceptions of their mothers' and fathers' parenting practices might change over the life course. Second, we could not examine the causal relationship between maternal employment and children's perceptions of their mothers' and fathers' parenting practices. It is possible that adults who feel that they were neglected by their parents in their childhood might overestimate the duration of their mothers' employment and that adults who remember that they grew up feeling very close to their parents might underreport the duration of their mothers' employment. Third, it would be better if more sophisticated measures of maternal employment were examined. Research has suggested that work conditions, such as autonomy and creativity in one's work, tend to influence how parents interact with their children at home (Greenberger, O'Neil, \& Nagel, 1994; Parcel \& Menaghan, 1994). Limited information about respondents' mothers' jobs was available in the MIDUS data, however. Fourth, we realize that the $R$-square values tend to be small across all models. It appears that there are many other factors that account for maternal and paternal parenting practices that we have not captured in these models. Finally, we focused on three aspects of parentingemotional support, discipline, and verbal or physical assaults - that have been commonly examined in previous studies. There are many other ways through which parents influence children, however. In Gerson's (2002) study, children mentioned that one of the best things about having an employed mother was having a good role model of hard work and dedication. Future quantitative research may examine 
different types of measures of children's perceptions of their parents, such as respect, role modeling, admiration, and guidance and how they vary by parental employment patterns.

To conclude, using adults' retrospective views of their mothers and fathers in childhood, this study provided additional evidence that maternal employment may alter the dynamics of parenting practices for both mothers and fathers in twoparent families. To some degree, these findings underscore the importance of gender in understanding the relationship between maternal employment and parenting practices. Future research should continue to investigate what accounts for the relationships between maternal employment, the child's gender, and parenting practices.

\section{NOTE}

An earlier version of the manuscript was presented at the 2005 Annual Meeting of the American Sociological Association, Philadelphia, PA.

\section{REFERENCES}

Amato, P. R. (1987). Family processes in one-parent, stepparent, and intact families: The child's point of view. Journal of Marriage and the Family, 49, $327-337$.

Amato, P. R. (1991). Psychological distress and the recall of childhood family characteristics. Journal of Marriage and the Family, 53, 1011 - 1019.

Amato, P. R. (1994). Father-child relations, motherchild relations, and offspring psychological wellbeing in early adulthood. Journal of Marriage and the Family, 56, 1031 - 1042.

Amato, P. R., \& Fowler, F. (2002). Parenting practices, child adjustment and family diversity. Journal of Marriage and Family, 64, 703 - 716.

Aquilino, W. S. (1997). From adolescent to young adult: A prospective study of parent-child relations during the transition to adulthood. Journal of Marriage and the Family, 59, 670 - 686.

Astone, N. M., \& McLanahan, S. S. (1991). Family structure, parental practices, and high school completion. American Sociological Review, 56, $309-$ 320.

Barnett, R. C., \& Rivers, C. (1996). She works/he works: How two-income families are happier, healthier, and better-off. Cambridge, MA: Harvard University Press.

Bedford, V. H. (1992). Memories of parental favoritism and the quality of parent-child ties in adulthood.
Journal of Gerontology: Social Sciences, 47, S149 S155.

Bianchi, S. M. (2000). Maternal employment and time with children: Dramatic change or surprising continuity? Demography, 37, $401-414$.

Blair-Loy, M. (2003). Competing devotions: Career and family among women executives. Cambridge, MA: Harvard University Press.

Brewster, K. L., \& Padavic, I. (2000). Change in gender ideology, 1977 - 1996: The contributions of intracohort change and population turnover. Journal of Marriage and the Family, 62, 477 - 487.

Bronfenbrenner, U., Alvarez, W. F., \& Henderson, C. R., Jr. (1984). Working and watching: Maternal employment status and parents' perceptions of their three-year-old children. Child Development, $55,1362-1378$.

Bryant, W. K., \& Zick, C. D. (1996). An examination of parent-child shared time. Journal of Marriage and the Family, 58, 227 - 237.

Bulcroft, R., Carmody, D. C., \& Bulcroft, K. A. (1996). Patterns of parental independence giving to adolescents: Variations by race, age, and gender of child. Journal of Marriage and the Family, 58, $866-883$.

Carr, D. (2002). The psychological consequences of work-family trade-offs for three cohorts of men and women. Social Psychology Quarterly, 65, $103-124$.

Chase-Lansdale, L., \& Owen, M. T. (1987). Maternal employment in a family context: Effects on infantmother and infant-father attachments. Child Development, 58, 1505 - 1512 .

Cohen, P. N., \& Bianchi, S. M. (1999). Marriage, children, and women's employment: What do we know? Monthly Labor Review, 122(12), 22 - 31.

Coley, R. L. (2003). Daughter-father relationships and adolescent psychological functioning in lowincome African American families. Journal of Marriage and Family, 65, 867 - 875.

Crouter, A. C., Bumpus, M. F., Maguire, M. C., \& McHale, S. M. (1999). Linking parents' work pressure and adolescents' well-being: Insights into dynamics in dual-earner families. Developmental Psychology, 35, 1453 - 1461.

Crouter, A. C., \& Crowley, M. S. (1990). School-age children's time alone with fathers in single- and dual-earner families: Implications for the fatherchild relationship. Journal of Early Adolescence, 10, $296-312$.

Desai, S., Chase-Lansdale, P. L., \& Michael, R. (1989). Mother or market?: Effects of maternal employment on the intellectual ability of 4-yearold children. Demography, 26, 545 - 561. 
Elder, G. H., Jr., \& Johnson, M. K. (2002). The life course and human development: Challenges, lessons, and new directions. In R. A. Settersten (Ed.), Invitation to the life course: Toward new understandings of later life (pp. 49 - 81). Amityville, NY: Baywood.

Galinsky, E. (1999). Ask the children: What America's children really think about working parents. New York: Morrow.

Gerson, K. (2002). Moral dilemmas, moral strategies, and the transformation of gender: Lessons from two generations of work and family change. Gender \& Society, 16, $8-28$.

Glass, J. (2000). Envisioning the integration of family and work: Toward a kinder, gentler workplace. Contemporary Sociology, 29, 129 - 143.

Goldberg, W. A., Greenberger, E., \& Nagel, S. K. (1996). Employment and achievement: Mother's work involvement in relation to children's achievement behaviors and mothers' parenting behaviors. Child Development, 67, 1512 - 1527.

Goode, W. J. (1960). A theory of role strain. American Sociological Review, 25, 483 - 496.

Greenberger, E., O'Neil, R., \& Nagel, S. K. (1994). Linking workplace and homeplace: Relations between the nature of adults' work and their parenting behaviors. Developmental Psychology, 6, $990-1002$.

Hochschild, A. R. (1989). The second shift. New York: Avon Books.

Hoffman, L., \& Youngblade, L. M. (1999). Mothers at work: Effects on children's well-being. New York: Cambridge University Press.

Khaleque, A., \& Rohner, R. P. (2002). Perceived parental acceptance-rejection and psychological adjustment: A meta-analysis of cross-cultural and intracultural studies. Journal of Marriage and Family, 64, 54 - 64 .

Knight, D. K., Broome, K. M., Cross, D. R., \& Simpson, D. D. (1998). Antisocial tendency among drug-addicted adults: Potential long-term effects of parental absence, support, and conflict during childhood. American Journal of Drug and Alcohol Abuse, 24, 361 - 375.

MacEwen, K. E., \& Barling, J. (1991). Effects of maternal employment experiences on children's behavior via mood, cognitive difficulties and parenting behavior. Journal of Marriage and the Family, 53, 635 - 644.

Marks, S., \& MacDermid, S. M. (1996). Multiple roles and the self: A theory of role balance. Journal of Marriage and the Family, 58, 417 - 432.

McLoyd, V. C., Cauce, A. M., Takeuchi, D., \& Wilson, L. (2000). Marital processes and parental socialization in families of color: A decade review of research. Journal of Marriage and the Family, $62,1070-1093$.

McLoyd, V. C., Jayaratne, T. E., Ceballo, R., \& Borquez, J. (1994). Unemployment and work interruption among African American single mothers: Effects on parenting and adolescent socioemotional functioning. Child Development, 65, $562-589$.

McLoyd, V., \& Smith, J. (2002). Physical disciple and behavior problems in African American, European American, and Hispanic children: Emotional support as a moderator. Journal of Marriage and Family, 64, 40-53.

MacArthur Foundation Research Network on Successful Midlife Development. (2005). The Technical Report on the Methodology of the MIDUS Survey. The John D. and Catherine T. MacArthur Foundation Research Network on Successful Midlife Development. Retrieved November 19, 2005, from, http://midmac.med.harvard.edu./tech. html.

Milkie, M. A., Mattingly, M. J., Nomaguchi, K. M., Bianchi, S. M., \& Robinson, J. P. (2004). The time squeeze: Parental statuses and feelings about time with children. Journal of Marriage and Family, $66,738-760$.

Milkie, M. A., Simon, R. W., \& Powell, B. (1997). Through the eyes of children: Youths' perceptions and evaluations of maternal and paternal roles. Social Psychology Quarterly, 60, 218 - 237.

Muller, C. (1995). Maternal employment, parental involvement, and mathematics achievement among adolescents. Journal of Marriage and the Family, $57,85-100$.

Nock, S. L., \& Kingston, P. W. (1988). Time with children: The impact of couples work-time commitments. Social Forces, 67, $59-85$.

Parcel, T. L., \& Menaghan, E. G. (1994). Early parental work, family social capital, and early childhood outcomes. American Journal of Sociology, 99, 972 - 1009.

Patterson, G. R., \& Stouthamer-Loeber, M. (1984). The correlation of family management practices and delinquency. Child Development, 55, 1299 1307.

Repetti, R. L., \& Wood, J. (1997). Effects of daily stress at work on mothers' interactions with preschoolers. Journal of Family Psychology, 11, 90 - 108.

Richards, M. H., \& Duckett, E. (1994). The relationship of maternal employment to early adolescent daily experience with and without parents. Child Development, 65, 225 - 236.

Roberts, R. E. L., \& Bengtson, V. L. (1993). Relationships with parents, self-esteem, and psychological 
well-being in young adulthood. Social Psychology Quarterly, 53, 263 - 277.

Rohner, R. P., Bourque, S. L., \& Elordi, C. A. (1996). Children's perceptions of corporal punishment, caretaker acceptance, and psychological adjustment in a poor, biracial southern community. Journal of Marriage and the Family, 58, 842 - 852.

Rossi, A. S. (2001). Developmental roots of adult social responsibility. In A. S. Rossi (Ed.), Caring and doing of others: Social responsibility in the domains of family, work, and community (pp. 227 - 320). Chicago: University of Chicago Press.

Rossi, A., \& Rossi, P. (1990). Of human bonding: Parent-child relations across the life course. New York: Aldine de Gruyter.

Sayer, L. C., Bianchi, S. M., \& Robinson, J. P. (2004). Are parents investing less in children? Trends in mothers' and fathers' time with children. American Journal of Sociology, 110, 1 - 43.

Scott, J., \& Alwin, D. (1998). Retrospective versus prospective measurement of life histories in longitudinal research. In J. Z. Giele, \& G. H. Elder, Jr. (Eds.), Methods of life course research (pp. 98 127). Thousand Oaks, CA: Sage.

Straus, M. A. (1991). Discipline and deviance: Physical punishment of children and violence and other crime in adulthood. Social Problems, 38, 133 - 154.

Straus, M. A., Hamby, S. L., Boney-McCoy, S., \& Sugarman, D. B. (1996). The revised Conflict Tactics Scales (CTS2): Development and preliminary psychometric data. Journal of Family Issues, 17, $283-316$.

Stuckey, M. E., McGhee, P. E., \& Bell, N. J. (1982). Parent-child interaction: The influence of maternal employment. Developmental Psychology, 18, 635 644.

Sugar, M. H. (1994). When mothers work, who pays? Westport, CT: Bergin \& Garvey.

Thomson, E., Mosley, J., Hanson, T. L., \& McLanahan, S. S. (2001). Remarriage, cohabitation, and changes in mothering behavior. Journal of Marriage and the Family, 63, $370-380$.

Tichamyer, A. R., \& Duncan, C. M. (1990). Poverty and opportunity structure in rural America. Annual Review of Sociology, 16, $67-86$.

Townsend, N. W. (2002). The package deal: Marriage, work, and fatherhood in men's lives. Philadelphia, PA: Temple University Press.

Turner, H. A., \& Muller, P. A. (2004). Long-term effects of child corporal punishment on depressive symptoms in young adults. Journal of Family Issues, 25, $761-782$.

Trimberger, R., \& MacLean, M. J. (1982). Maternal employment: The child's perspective. Journal of Marriage and the Family, 44, 469 - 475.

Wenk, D., Hardesty, C. L., Morgan, C. S., \& Blair, S. L. (1994). The influence of parental involvement on the well-being of sons and daughters. Journal of Marriage and the Family, 56, 229 234.

Wodak, R., \& Schulz, M. (1985). The language of love and guilt: Mother-daughter relationships in cross-cultural perspective. Amsterdam: John Benjamins.

Yeung, W. J., Sandberg, J. F., Davis-Kean, P. E., \& Hofferth, S. L. (2001). Children's time with fathers in intact families. Journal of Marriage and the Family, 63, 136 - 154. 